\title{
Socio-Economic and Cultural Influence on Vitamin A Intake of Lactating Mothers in Ngaoundere Cameroon
}

\author{
W. Damndja Ngaha ${ }^{1}$, Edith N. Fombang ${ }^{1}$ and R. Aba Ejoh ${ }^{1,2, *}$ \\ ${ }^{1}$ Department of Food Sciences and Nutrition, National School of Agro-Industrial Sciences, University of \\ Ngaoundere, Ngaoundere, Cameroon \\ ${ }^{2}$ Department of Food and Bioresource Technology, College of Technology, The University of Bamenda, \\ Bambili, Cameroon
}

\begin{abstract}
Background: Vitamin A deficiency (VAD) is a widespread public health problem in developing nations affecting greatly pregnant and lactating women. The intake of Vitamin A rich foods highly recommended to reduce the prevalence in these vulnerable groups are greatly influenced by the level of education, geographic origin and differences in food habits.

Aims of the Study: To evaluate the Influence of socio-economic, cultural, geographic origin, and demographic factors on vitamin $\mathrm{A}$ (VA) intake of lactating mothers in Ngaoundere, Cameroon.

Method: A total of 100 lactating mothers attending pediatric consultations at four major health structures in Ngaoundere were involved in the survey. A questionnaire was used to get information on socio-economic, cultural, demographic factors, geographic origin, anthropometric parameters and culinary practices. Dietary intake was assessed using a 24hour dietary recall method. Meals potentially rich in VA consumed by these women were collected, their carotenoids contents quantified and VA activity determined.
\end{abstract}

Results: Average VA intake of lactating women of Northern origin was significantly $(p<0.05)$ lower $(595.2 \pm 60.4 \mu \mathrm{g} / \mathrm{day})$ than that of women of Southern origin $(737.6 \pm 55.6 \mu \mathrm{g} / \mathrm{day})$, although both were below the recommended intake of $850 \mu \mathrm{g} / \mathrm{day}$. VA intake was also higher in the more educated women. Marital status, number of children, age of the mother and body mass index did not significantly influence the daily VA intake of the women. Lactating women of Northern origin, with three or more children and having no formal education, are more at risk of acute VA Deficiency.

Conclusion: While the level of education influenced the VA intake in lactating women from the Northern Region, the age of the baby influenced those from the Southern Region.

Keywords: Culinary practices, Lactating mother, Socio-economic factors, Vitamin A intake, Vitamin A Deficiency.

\section{INTRODUCTION}

Vitamin $A$ is found in the diet as preformed retinol from animal sources and provitamin A carotenoids from vegetable sources [1]. The major consequences of Vitamin A Deficiency (VAD) are xerophthalmia, corneal blindness, anemia, stunted growth, impaired immunity, increased severity of infection and mortality [2]. VAD usually results from an inadequate dietary intake amongst other factors linked to their absorption and metabolism. Children less than 5 years, pregnant and lactating women are the most vulnerable groups due to their vitamin A needs at these critical stages of life [3].

Vitamin A deficiency (VAD) is a widespread public health problem in developing nations and affects more than 130 million preschool children [4]. In Africa, 28\% of children under 5 are affected. The situation is more serious in the sub-Saharan Africa region (40\%) [5], and particularly in the CEMAC sub-region, with over $54 \%$ of pregnant women affected [6]. In Cameroon, $40 \%$ of

*Address correspondence to this author at the Department of Food and Bioresource Technology, College of Technology, University of Bamenda, Bambili, Cameroon; Tel: +237 676179833; E-mail: ejohrab@yahoo.com

E-ISSN: 1929-5634/16 children less than 5 years suffer from VAD, and this situation is more worrying in the Northern Regions (Adamawa, North and Far-North Regions) where $62.5 \%$ of children are affected [7]. There is limited information on VAD among lactating women in this region. Food consumption as well as the quantity and quality of the diet are influenced by social factors $[8,9]$. A previous study showed that vitamin A intake was strongly influenced by the level of education, geographic origin and body mass index for pregnant women in Ngaoundere [10]. In an attempt to evaluate the VAD risk in vulnerable population groups and the different factors that influence the consumption of vitamin $A$, this study sets out to determine the variability in vitamin $A$ intake of lactating mothers $(0-4$ months) in Ngaoundere with respect to their geographic origin, socio-economic, anthropometric, cultural and demographic characteristics.

\section{MATERIALS AND METHOD}

\section{Location of the Study Site}

The study took place in Ngaoundere town, located at the North of the Adamawa Region of Cameroon, 
more precisely on the Adamawa plateau. Foulbe (or Peuls) and Mboum are the most significant ethnic groups [11], but there are also Gbaya, Tikar, and other ethnic groups coming from the whole of Cameroun. The population is mainly Moslem, but the catholic and protestant churches are also well established [1]. The Koranic School has priority over the French and English speaking schools [12]. The climate is almost moderate since this zone of arborous savanna is located in a highland. One distinguishes two seasons, dry and rainy seasons. The variations in temperature are rather significant in dry season which is marked by the Harmattan, a dry and hot wind coming from the North. The rainy season, is marked by discontinuous rains which are sometimes violent [11]. Cattle rearing (Zebu Gudali type) and the cultivation of tubers (Ipomea batata, Dioscorea rotundata), vegetables (Moringa oleifera, Solanum nigrum, Hibiscus sabdarifa) and cereals (Zea mays, Panicum miliaceum L.) are the principal activities of this low income population [1].

\section{Inclusion of Participants in the Study}

To easily reach the target population, lactating women, carrying out vaccination and pediatric consultations of their babies in four health structures in the town of Ngaoundere were recruited for the study. These health structures were the Regional Hospital, the Protestant Hospital, the health district of Boumdjéré and the integrated health center of Sabongari. The sampled population therefore came from different backgrounds; urban, semi-urban and rural areas, from varied socio-economic, cultural and demographic groups, with different levels of education.

Any lactating woman aged from 15 to 40 years old, practicing exclusive breast-feeding, having a baby of less than 4 months, being under no medication or particular diet, and having given her consent was recruited. All those who did not meet these criteria were excluded from the study. The recruitment period lasted two weeks, from $22^{\text {nd }}$ April to $10^{\text {th }}$ May 2013, period during which socio-demographic information was collected and anthropometric data measured. These included age, weight, height, level of education, professional status, marital status, religion, number of children and age of the baby. Informed consent was obtained from the women and the study period on the field lasted for two months with the effective participation of 100 lactating women. Ethical approval for this study was obtained from the ethical committee of the Regional Hospital in Ngaoundere.

\section{Data Collection}

Demographic, anthropometric, cultural and socioeconomic data of the lactating women were collected through interviews, using structured questionnaires to obtain information on variables such as age, weight, height, level of education, marital status, religion, geographic origin, age of the baby, number of births and professional status. Body Mass Index (BMI) was calculated from weight and height measurements using the Quetelet index:

$\mathrm{BMI}=\mathrm{W} / \mathrm{H}^{2}(\mathrm{~W}$, is weight in $\mathrm{Kg}$ and $\mathrm{H}$, is Height in $\mathrm{m})$.

The lactating women were separated into two groups (those from Northern origin and those from Southern origin) as describe in a recent study [10] and based on the fact that the cultural and culinary practices differ especially with respect to use of palm oil and carrots.

Food and nutrients intake was assessed using 24 hour dietary recall as described previously [1]. Meal samples were collected at home and carotenoid content determined using AOAC method [13]. VA activity was calculated from this, based on the assumption that $12 \mu \mathrm{g}$ of dietary carotenoid yields $1 \mu \mathrm{g}$ of vitamin A activity or $1 \mu \mathrm{gg}$ of dietary carotenoids equals $0.083 \mu \mathrm{g}$ RE [14]. Vitamin A from animal products was obtained from Food Composition Tables $[15,16]$. Total vitamin A intake of lactating mothers was thus the sum of intakes from vegetable and animal portions of various dishes consumed during the study period. The daily vitamin $A$ intake was therefore the mean consumption per mother per day during the study period, and the general intake for each group of women was the mean consumption for all the women in that group.

\section{Statistical Analysis}

The data obtained in this study was subjected to analysis of variance (ANOVA) and means separated using the least significant difference test with the statistical software Statgraphics centurion at the 5\% level of significance. Microsoft Excel 2013 and Minitab 16 were used to generate the graph and the Multiple Component Analysis respectively. Where appropriate, percentages (\%) were calculated. Results are presented as means and standard deviation of three determinations. 


\section{RESULTS}

\section{Anthropometric, Cultural and Socioeconomic Characteristics}

The distribution of the studied population with respect to measured characteristics is presented in Table 1. The study was carried out in the cosmopolitan town of Ngaoundere, where a majority of the women (68) originated from the Northern Regions of Cameroon (Adamawa, North and Far North Regions) as compared to 32 from the Southern Regions. 31\% of Northern mothers never attended school as against $0 \%$ of the Southern mothers thus a high illiteracy rate among the Northern mothers. This was confirmed by the other statistics concerning level of education with $38 \%$ and
$1 \%$ of the Northern women having secondary and University education respectively, against $59 \%$ and $22 \%$ of the Southern mothers for the same levels of education. More lactating mothers from Northern Regions (29\%) than those of Southern Regions (19\%) were limited to primary school. Approximately half of the women of Southern origin (44\%) were workers, which means they had a stable job compared to only $19 \%$ of the women of the Northern origin, who were predominantly housewives $(68 \%)$ with no income generating activity. There was no student among mothers of Northern origin while $7 \%$ of Southern mothers were students. There were more school girls among the Northern women (13\%) than those from the South $(9 \%)$. Concerning marital status, more of the

Table 1: Socio-Demographic and Anthropometric Parameters of the Studied Population

\begin{tabular}{|c|c|c|c|c|}
\hline \multirow{2}{*}{ Parameters } & \multirow{2}{*}{ Range } & \multicolumn{2}{|c|}{ Number of women $\mathbf{n}$ (percentage) } & \multirow{2}{*}{ Total } \\
\hline & & Northern & Southern & \\
\hline \multirow{4}{*}{ Level of education } & None & $21(31)$ & $0(0)$ & 21 \\
\hline & Primary & $20(29)$ & $6(19)$ & 26 \\
\hline & Secondary school & $26(38)$ & $19(59)$ & 45 \\
\hline & University & $1(1)$ & $7(22)$ & 8 \\
\hline \multirow{2}{*}{ Marital status } & Married & $58(85)$ & $19(59)$ & 77 \\
\hline & Single & $10(15)$ & $13(41)$ & 23 \\
\hline \multirow{2}{*}{ Religion } & Muslim & $39(57)$ & $2(6)$ & 41 \\
\hline & Christian & $29(43)$ & $30(94)$ & 59 \\
\hline \multirow{4}{*}{ Number of children } & 0 & $19(28)$ & $6(19)$ & 25 \\
\hline & 1 & $13(19)$ & $13(41)$ & 26 \\
\hline & 2 & $12(18)$ & $5(15)$ & 17 \\
\hline & $\geq 3$ & $24(35)$ & $8(25)$ & 32 \\
\hline \multirow{3}{*}{ Age of the mother (years) } & [15-20] & $13(19)$ & $3(9)$ & 16 \\
\hline & [20-30] & $38(56)$ & $18(56)$ & 56 \\
\hline & [30-40] & $17(25)$ & $11(35)$ & 28 \\
\hline \multirow{4}{*}{ Age of the baby (months) } & $<1$ & $8(12)$ & $3(9)$ & 11 \\
\hline & [1-2] & $25(37)$ & $10(31)$ & 35 \\
\hline & [2-3] & $22(32)$ & $13(40)$ & 35 \\
\hline & [3-4] & $13(19)$ & $6(20)$ & 19 \\
\hline \multirow{4}{*}{ Socio-professional status } & Housewife & $46(68)$ & $13(40)$ & 59 \\
\hline & Worker & $13(19)$ & $14(44)$ & 27 \\
\hline & Schoolgirl & $9(13)$ & $3(9)$ & 12 \\
\hline & Student & $0(0)$ & $2(7)$ & 2 \\
\hline \multirow{3}{*}{ BMI $\left(\mathrm{kg} / \mathrm{m}^{2}\right)$} & {$[18,5-24,9]$} & $37(55)$ & $14(44)$ & 51 \\
\hline & {$[25-29,9]$} & $26(38)$ & $14(44)$ & 40 \\
\hline & {$[30-34,9]$} & $5(7)$ & $4(12)$ & 9 \\
\hline Geographic origin & Whole population & 68 & 32 & 100 \\
\hline
\end{tabular}


women of Northern origin (85\%) were married compared to women of Southern origin (59\%). For the number of children per woman $53 \%$ of Northern mothers have at least three children ( 2 children in addition to the baby on breast-milk) compared to only $40 \%$ in Southern lactating women. Generally, $89 \%$ of the babies were aged one month or more while only $11 \%$ were less than one month. With $19 \%$ of teenage mothers aged between 15 and 20 years old, women of Northern origin give birth more precociously than those from Southern origin $(9 \%)$ and on the other hand, with $35 \%$ of women aged between 30 and 40 years, women of Southern origin give birth at a later stage in life than those from Northern origin (25\%). Irrespective of geographic origin, over $50 \%$ of the women $(75 \%$ of Northern origin and $65 \%$ of Southern origin) were under 30 years of age. More so, according to their Body Mass Index, approximately half of the women in each group (56\% in Southern mothers and $45 \%$ in Northern mothers) had poor nutritional status. About $44 \%$ and $38 \%$ of women were overweight amongst the women from Southern and Northern origin respectively, while $12 \%$ and $7 \%$ showed signs of primary obesity. More than half $(59 \%)$ of the studied women population were Christians in this Muslim predominant region.

\section{Consumption of Vitamin A Rich Foods}

Dishes potentially rich in vitamin A consumed by the lactating mothers during the study period are recorded in Table 2. In the course of the two months study period, Ngaoundere lactating mothers originating from Northern Cameroon consumed predominantly five dishes with high VA potential. These dishes are prepared using leafy vegetables like Adansonia digitata (Baobab leaves), Hibiscus sabdarifa (Folere), Manihot esculenta (Hako mbaï), Moringa oleifera (Guiligandja) and Corchorus olitorius (Lalo). In contrast, lactating women originating from the Southern part of the country consumed more VA rich dishes (eight) prepared using vegetables such as Gnetum africanum (Eru), Solanum nigrum (Zom), Vernonia amygdalina (Ndole) and Amaranthus hybridus (Folong) with variations in the methods of preparation. Some use red palm oil and others, carrots and tomatoes (Table 2). Except the dish made with Guiligandja (5.01 mg of VA), most of dishes consumed by Southern women are richer in vitamin $\mathrm{A}$ (2.77 to $6.80 \mathrm{mg}$ of $\mathrm{VA}$ as against 2.48 to $3.13 \mathrm{mg}$ of VA for women of Northern origin). Mothers from Southern origin consume more yellow maize than those coming from Northern Regions who preferably consume white maize (Table 2), yellow maize being richer in carotenoids.

\section{Daily Vitamin A Intake of Studied Population}

Table 3 presents the daily vitamin A intake per mother with respect to their geographic origin. The average intake of vitamin A for the Ngaoundere lactating women originating from the Southern Regions is $737.6 \mu \mathrm{g} /$ day as opposed to $595.2 \mu \mathrm{g} / \mathrm{day} /$ woman from Northern origin. Regardless of the socioprofessional, demographic and anthropometric characteristics, the vitamin A intake of women of Northern origin was generally significantly lower than that of women of Southern origin (Table 3). VA intake of lactating mothers from the Northern Regions was significantly $(p<0.05)$ influenced by their level of education. The higher the level of education, the higher the consumption of vitamin A rich foods. For mothers from the Southern Regions, VA intake was significantly $(p<0.05)$ influenced by the age of the baby. Mothers

Table 2: Dishes Potentially Rich in VA Consumed by Pregnant Women of Northern and Southern Origin

\begin{tabular}{|c|c|c|c|c|c|}
\hline \multicolumn{3}{|c|}{ Women from Northern-Cameroon } & \multicolumn{3}{|c|}{ Women from Southern-Cameroon } \\
\hline Dishes & Water (\%) & V.A Eq* $(m g)$ & Dishes & Water (\%) & V.A Eq* $(m g)$ \\
\hline Bokko $^{1}$ & $87.15 \pm 3.22$ & 3.13 & $\operatorname{Eru}^{6}$ (with palm oil) & $75.12 \pm 1.53$ & 6.80 \\
\hline Hako Mbaï ${ }^{2}$ & $82.71 \pm 2.56$ & 2.30 & Sauce Zom ${ }^{7}$ (with groundnuts) & $81.72 \pm 2.05$ & 3.42 \\
\hline Folere $^{3}$ & $83.95 \pm 2.48$ & 2.59 & Sauce Ndole ${ }^{8}$ (with groundnuts) & $79.35 \pm 1.79$ & 2.91 \\
\hline Lalo $^{4}$ & $84.04 \pm 2.41^{\mathrm{fg}}$ & 2.48 & Sauce Folong ${ }^{9}$ (with groundnuts) & $81.53 \pm 3.16$ & 2.77 \\
\hline Giligandja $^{5}$ & $80.17 \pm 3.09$ & 5.01 & Fried zom ${ }^{7}$ (with tomato and carrot) & $78.72 \pm 2.44$ & 5.28 \\
\hline \multirow[t]{3}{*}{ White corn fufu ${ }^{10}$} & $67.15 \pm 1.14$ & 0,03 & Fried Ndole ${ }^{8}$ (with tomato) & $76.34 \pm 2.31$ & 4.83 \\
\hline & & & Fried Folong $^{9}$ (with tomato) & $78.56 \pm 3.09$ & 4.62 \\
\hline & & & Yellow corn fufu ${ }^{10}$ & $66.84 \pm 2.01^{\mathrm{c}}$ & 0,16 \\
\hline
\end{tabular}

${ }^{1}$ Adansonia digitata, ${ }^{2}$ Manihot esculenta, ${ }^{3} \mathrm{Hibiscus}$ sabdarifa, ${ }^{4} \mathrm{C}$ orchorus olitorius. ${ }^{5}$ Moringa oleifera, ${ }^{6} \mathrm{G}$ etum africanum, ${ }^{7}$ Solanum nigrum, ${ }^{8}$ Vernonia amygdalina, ${ }^{9}$ Amaranthus hybridus, ${ }^{10}$ Zea mays; *Vitamin A Equivalent for $100 \mathrm{~g}$ (Dry weight basis). 
Table 3: Vitamin A Intake According to Geographic Origin, Socio-Professional, Cultural and Demographic Parameters*

\begin{tabular}{|c|c|c|c|c|}
\hline \multirow{2}{*}{ Parameters } & \multirow{2}{*}{ Range } & \multicolumn{3}{|c|}{ Daily vitamin A intake ( $\mu \mathrm{g} /$ day) } \\
\hline & & Northern & Southern & General \\
\hline \multirow{4}{*}{ Level of Education } & None & $539.4 \pm 31.0^{\mathrm{a}}$ & $/ /$ & $539.4 \pm 31.0^{\mathrm{a}}$ \\
\hline & Primary & $583.6 \pm 42.2^{\mathrm{ab}}$ & $727.0 \pm 88.8^{\mathrm{a}}$ & $619.4 \pm 83.7^{\mathrm{ab}}$ \\
\hline & Secondary & $642.3 \pm 43.4^{b}$ & $737.7 \pm 53.8^{a}$ & $683.2 \pm 67.3^{\mathrm{bc}}$ \\
\hline & University & $708.0 \pm 0.0^{c}$ & $747.7 \pm 28.6^{\mathrm{a}}$ & $739.8 \pm 30.5^{c}$ \\
\hline \multirow{2}{*}{ Marital status } & Married & $583.5 \pm 54.9^{\mathrm{a}}$ & $740.5 \pm 68.1^{a}$ & $622.7 \pm 89.7^{\mathrm{abc}}$ \\
\hline & Single & $665.7 \pm 43.6^{\mathrm{a}}$ & $733.2 \pm 32.9^{a}$ & $704.3 \pm 50.2^{\text {cd }}$ \\
\hline \multirow{2}{*}{ Religion } & Muslim & $564.6 \pm 44.9^{\mathrm{a}}$ & $675.0 \pm 0,0^{\mathrm{a}}$ & $569.0 \pm 49.2^{\mathrm{ab}}$ \\
\hline & Christian & $636.1 \pm 54.6^{\mathrm{a}}$ & $740.9 \pm 55.1^{a}$ & $689.9 \pm 75.8^{\text {bcd }}$ \\
\hline \multirow{4}{*}{ Number of children } & 0 & $639.7 \pm 48.6^{\mathrm{a}}$ & $721.7 \pm 41.8^{a}$ & $660.2 \pm 58.5^{\mathrm{a}}$ \\
\hline & 1 & $583.7 \pm 43.1^{a}$ & $746.6 \pm 40.7^{\mathrm{a}}$ & $665.2 \pm 93.4^{\mathrm{a}}$ \\
\hline & 2 & $591.9 \pm 70.7^{\mathrm{a}}$ & $690.3 \pm 112.4^{a}$ & $621.4 \pm 91.7^{\mathrm{a}}$ \\
\hline & $\geq 3$ & $567.3 \pm 56.2^{\mathrm{a}}$ & $764.2 \pm 34.4^{\mathrm{a}}$ & $616.5 \pm 101.1^{\mathrm{a}}$ \\
\hline \multirow{3}{*}{ Age of mother (years) } & {$[15-20]$} & $605.9 \pm 55.5^{\mathrm{a}}$ & $729.0 \pm 41.0^{\mathrm{a}}$ & $630.5 \pm 72.7^{\mathrm{a}}$ \\
\hline & {$[20-30]$} & $606.0 \pm 58.3^{\mathrm{a}}$ & $725.9 \pm 68.3^{\mathrm{a}}$ & $643.7 \pm 82.8^{\mathrm{a}}$ \\
\hline & [30-40] & $560.8 \pm 61.8^{\mathrm{a}}$ & $758.4 \pm 30.8^{\mathrm{a}}$ & $642.2 \pm 112.1^{a}$ \\
\hline \multirow{4}{*}{ Age of the baby (months) } & $<1$ & $615.0 \pm 86.8^{\mathrm{a}}$ & $716.5 \pm 53.0^{\mathrm{ab}}$ & $644.0 \pm 89.1^{\mathrm{a}}$ \\
\hline & {$[1-2]$} & $591.3 \pm 50.6^{a}$ & $784.6 \pm 28.5^{\mathrm{b}}$ & $638.0 \pm 94.9^{\mathrm{a}}$ \\
\hline & [2-3] & $603.4 \pm 52.9^{a}$ & $733.8 \pm 64.8^{\mathrm{ab}}$ & $656.6 \pm 87.4^{\mathrm{a}}$ \\
\hline & [3-4] & $576.0 \pm 76.9^{\mathrm{a}}$ & $698.0 \pm 15.9^{a}$ & $616.7 \pm 86.2^{\mathrm{a}}$ \\
\hline \multirow{4}{*}{ Socio-professional status } & Housewife & $570.0 \pm 48.1^{\mathrm{a}}$ & $755.5 \pm 63.0^{\mathrm{a}}$ & $610.4 \pm 93.8^{\mathrm{a}}$ \\
\hline & Worker & $654.7 \pm 49.9^{\mathrm{a}}$ & $720.6 \pm 53.3^{\mathrm{a}}$ & $689.6 \pm 60.4^{\mathrm{ab}}$ \\
\hline & Schoolgirl & $638.3 \pm 43.6^{a}$ & $700.0 \pm 00.0^{\mathrm{a}}$ & $647.1 \pm 46.1^{\mathrm{ab}}$ \\
\hline & Student & $/ /$ & $761.5 \pm 23.3^{\mathrm{a}}$ & $761.5 \pm 23.3^{b}$ \\
\hline \multirow{3}{*}{$\mathrm{BMI}\left(\mathrm{kg} / \mathrm{m}^{2}\right)$} & [19-25] & $594.8 \pm 55.7^{\mathrm{a}}$ & $749.1 \pm 53.8^{a}$ & $629.8 \pm 78.6^{a}$ \\
\hline & [25-30] & $604.9 \pm 67.4^{a}$ & $754.7 \pm 60.6^{a}$ & $658.8 \pm 97.2^{\mathrm{a}}$ \\
\hline & [30-35] & $547.0 \pm 49.2^{\mathrm{a}}$ & $784.0 \pm 19.8^{\mathrm{a}}$ & $625.8 \pm 113.8^{a}$ \\
\hline Geographic origin & Whole population & $595.2 \pm 60.4^{1}$ & $737.6 \pm 55.6^{2}$ & $641.1 \pm 88.9^{12}$ \\
\hline
\end{tabular}

*Values followed by the same letter in a column indicates no significant difference $(p>0.05)$ in VA intake; *Values followed by different figures in a row indicates a significant difference $(p<0.05)$ in VA intake.

with babies aged between one and two months consume more vitamin A rich foods. In both study groups, VA intake of Christians is higher than that of Muslims and this was the same with married mothers whose VA consumption was higher than those of single mothers. In general for all the studied population, only the level of education and the socio-professional status that significantly $(p<0.05)$ influenced the daily vitamin A intake of the women, with the intake of women having no education being significantly $(p<0.05)$ lower than that of women who have been to school, and the VA intake of student being significantly $(p<0.05)$ higher than those of housewives. The number of children, age of the mother and BMI had no significant influence $(p>0.05)$ on daily vitamin $A$ intake of these pregnant women.

\section{Vitamin A Deficiency Risk with Respect to Geographic Origin}

Figure 1 presents the level of vitamin A among the studied population according to the geographic origin. Ngaoundere lactating women from Northern origin are more at risk of VAD than those from Southern part of the country. About $50 \%$ of lactating women from Northern origin are at risk of acute VAD $(500-649 \mu \mathrm{g})$ 


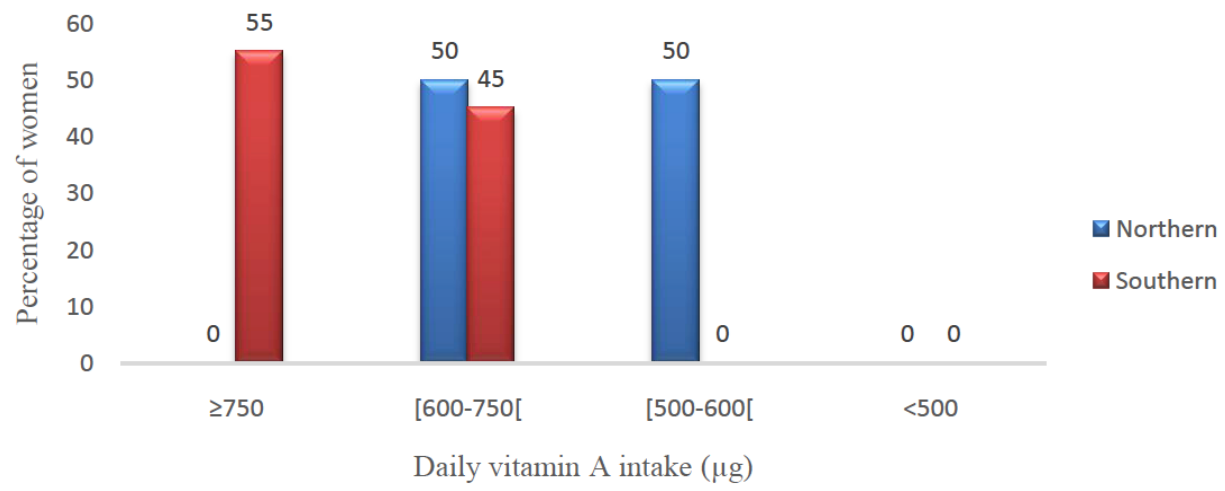

Figure 1: VAD risk with respect to geographic origin of lactating women.

and $50 \%$ at risk of slight VAD $(600-749 \mu \mathrm{g})$, while $45 \%$ of women from Southern origin are at risk of slight VAD and $55 \%$ cover their VA needs ( $\geq .750 \mu \mathrm{g} /$ day).

\section{Correlation between the Studied Parameters and VAD Risk}

Figure 2 presents the degree of correlation between the studied parameters and VAD risks. From this figure lactating mothers of Northern origin are mostly Muslims, housewives, illiterates, with three or more children and are more exposed to acute VAD while mothers of Southern origin, who are not exposed to risk of VAD are mostly Christians, workers or students, with only one child and have reached University level of education.

\section{DISCUSSION}

With daily VA intake of $595.2 \pm 60.4 \mu \mathrm{g}$ for Ngaoundere lactating mothers from the Northern Regions and $737.6 \pm 55.6 \mu \mathrm{g}$ for those of the Southern Regions (Table 3), it appears that the intake of vitamin A rich foods in Cameroon is significantly $(p<0.05)$ influenced by geographic origin and cultural values as opposed to food availability. These results corroborate those of a study carried out in the town of Ngaoundere on VAD risk amongst pregnant women [10] and are also similar to earlier findings in Yaoundé city where there was a relationship between the geographic origin of a household and food behavior [8]. The difference in VA intake of Northern and Southern women could principally be explained by their differences in food

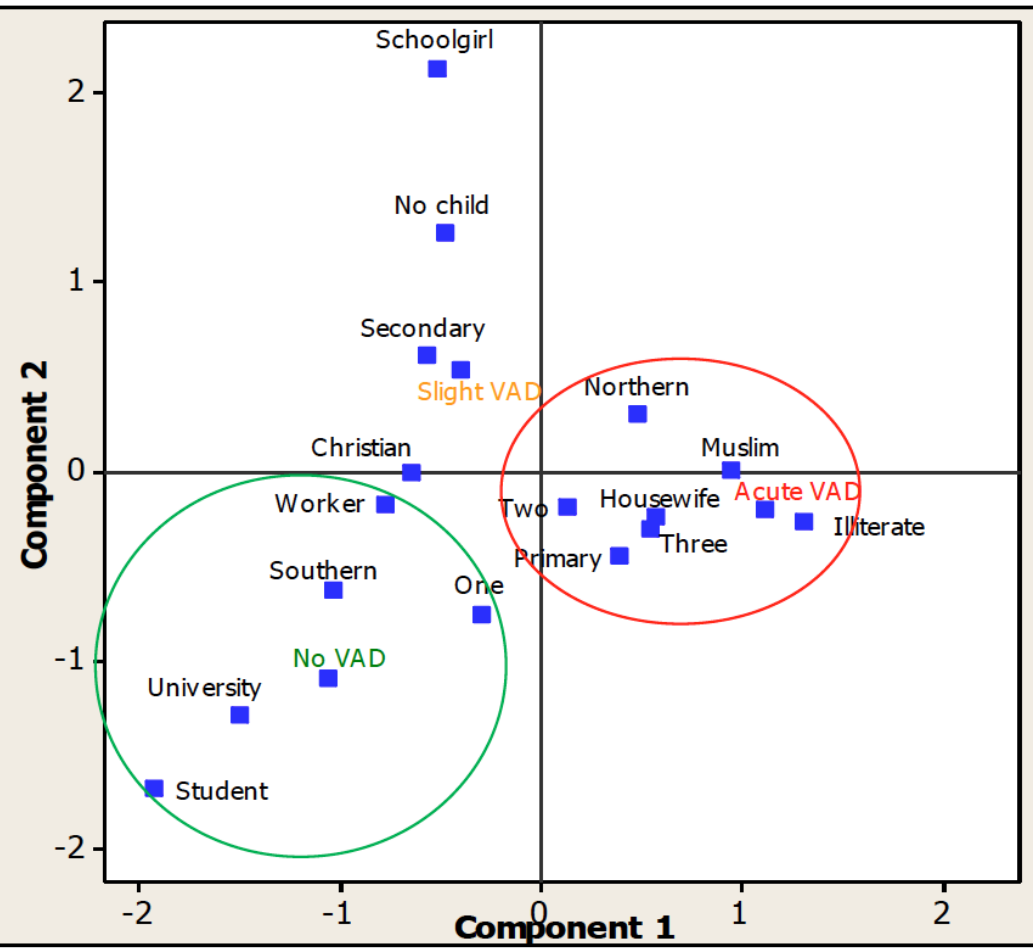

Figure 2: Correlation between studied parameters and Vitamin A Deficiency (VAD). 
habits (Table 2). Dishes consumed by Southern women have higher vitamin A contents, because of the different types of vegetables used in their preparation. Carotenoids content varies with the type of green leafy vegetable as reported by Djuikwo et al. [17]. Dishes that included S. nigrum, G. africanum, A. hybridus and $V$. amygdalina that are mostly consumed by lactating women from Southern origin are richer in provitamin $\mathrm{A}$ than those that use $A$. digitata, $M$ esculenta, $H$. sabdarifa and $C$. olitorus [17] mostly consumed by women of Northern origin. In addition, women originating from the Southern Regions have the culture of using red palm oil, carrots and tomatoes in their cooking, which are rich sources of $\beta$-carotene and other carotenoids [18]. On the contrary the women originating from Northern Cameroon do not have this culture. Southern women use red palm oil for the preparation of dishes like Eru, koki and zom. Furthermore, all women of Southern origin (100\%) consumed yellow maize in different forms (porridge, couscous, cake and whole grains) against only $68 \%$ of Northern women, with $57 \%$ of them having a consumption rate of twice or less per week. Women of Southern origin also consume other foods like chicken eggs which are richer in vitamin A (200 $\mu$ g of vitamin A) [16], and this is not the case with most of lactating women of Northern origin.

The general daily vitamin $A$ intake increased significantly $(p<0.05)$ from $539.4 \pm 31.0 \mu \mathrm{g}$ for mothers who had never gone to school to $739.8 \pm 30.5 \mu \mathrm{g}$ for those who reached university. This implies, the more educated a mother is, the better her vitamin A intake irrespective of origin, although the quantities consumed are higher for women from Southern origin compared to those of Northern origin. A similar trend was reported by Fombang et al. [10] with pregnant women of the same town. The level of education is thus an important factor to take into consideration when elaborating food policies and education programs. Certainly because of their illiteracy, women with low educational background can neither read nor write, and for some cannot even express themselves in French or English, the official languages in Cameroon. They therefore cannot grasp the messages in the multiple nutritional public awareness campaigns on radio, television, and even in the hospitals and health centers where they go for their consultations. Added to this, is the fact that they probably do not understand the importance of nutrition in their life and those of their children. It has been shown that women who receive minimal education are generally more aware, than those who have no education at all [19]. Education can enable women make correct decisions about food choices, and to have greater access to household resources that are important for their nutritional status [20]. A comparative study on maternal malnutrition in ten Sub-Saharan African countries [21] and another study in Ethiopia [22] showed that the higher the level of education, the lower the proportion of undernourished women. These results are different from that of WHO/FAO [6], where there was no significant difference in vitamin $A$ intake between women who were married and those single, and between their different levels of education. This could be due to the fact that in a WHO study, there were only women from secondary school and university, compared to this study where approximately $50 \%$ of the pregnant women from Northern Region had never gone to school. These results are also different from those of Tabuna and Tanoe [8]. This difference could be due to the difference in the study site given that Tabuna and Tanoe worked in Yaoundé, a city located in the southern part of Cameroon most of them having the same characteristics as the Ngaoundere women of Southern origin. Statistics of the population in our study showed that lactating women from Southern Regions were more educated than those of Northern origin and this is reflected in statistics of the level of education in these two regions [23].

The age of the baby significantly $(p<0.05)$ influences vitamin A consumption of the Southern mothers with $784.6 \pm 28.5 \mu \mathrm{g}$ for those having a baby aged from one to two months, higher than $698.0 \pm 15.9$ $\mu \mathrm{g}$ for those having a baby from three to four months. This significant variation can be explained by the fact that when the child crossed the first quarter, the family attention around the mother drops gradually, as the care taker that normally comes to assist the mother after delivery departs. Another explanation is at the professional level because the end of the first quarter also marks the end of the maternity leave, and the resumption of work considerably disturbs their diet by causing the reduction of the food intake.

The socio-professional status of the women had no significant $(p>0.05)$ influence on their vitamin A intake, irrespective of origin. This could be explained by the fact that culinary practices were similar among each group of mothers, and according to the 24 hour dietary recall, the women ate most of their meals at home, certainly due to the fact that they are young mothers and have to stay at home to feed their babies who are under exclusive breast-feeding. Other studies have shown no significant variation in vitamin A intake [6] or food habits in general [23] with socio-professional 
status. This suggests that food consumption patterns and food habits are more rooted in Cameroonian cultures than in socio-professional status.

Though, the average daily vitamin A intake of mothers from the Northern Regions $(595.2 \mu \mathrm{g} /$ day $)$ is significantly $(p<0.05)$ lower than that of mothers from the Southern Regions $(737.6 \mu \mathrm{g} / \mathrm{day})$, both consumed less VA than the $850 \mu \mathrm{g}$ recommended daily. However, lactating mothers from Northern origin are the only concerned with acute $V A D$, which means they are the most at risk of VAD with none $(0 \%)$ of them covering their daily VA needs contrary to Southern lactating women who are in the majority (55\%) VAD free (Figure 1). This is due to the fact that for the mothers of Northern origin, many risk factors are put together such as food habits, illiteracy, high number of children in the family which could all contribute to reduce food intake, and these factors are strongly linked to acute VAD (Figure 2). It can therefore be suggested that geographic origin and level of education of lactating mothers in Ngaoundere town are important factors influencing their vitamin A status. Thus a lactating woman originating from the Northern part of Cameroon and having no formal education is strongly predisposed to foods low in vitamin $A$, and consequently presents a higher risk of developing acute VAD.

\section{CONCLUSION}

This study reveals suboptimal dietary intake of vitamin $A(<850 \mu \mathrm{g})$, insufficient to cover the needs of lactating mothers in Ngaoundere Cameroon. Geographic origin and socio-professional status significantly influenced dietary intake of vitamin A of the lactating women. While the level of education influenced the VA intake in lactating women of Northern origin, the age of the baby was the principal factor that influenced those of the Southern origin. A lactating woman originating from the Northern part of Cameroon, who has never been to school and who has three or more children is strongly exposed to acute VAD. Nutritional intervention programs designed to reduce the prevalence of VAD should take into consideration these variables. Improving the level of scholarisation of the girl child and changing culinary practices, should be one of the priority areas of government action towards alleviating VAD.

\section{ACKNOWLEGEMENT}

We are grateful to the lactating mothers who participated in this study, giving of their time without any financial compensation.

\section{REFERENCES}

[1] Ngaha DW, Fombang EN, Ejoh RA. Dietary Intake of Vitamin $A$ and Macronutrients among Pregnant Women in Ngaoundere Town, Adamawa Region, Cameroon. Food and Nutr Sci 2014; 5: 2071-2080. http://dx.doi.org/10.4236/fns.2014.521219

[2] West Jr, Keith P. Vitamin A Deficiency and Child Health, Survival and Vision. Center for Human Nutrition, Bloomberg School of Public Health, Johns Hopkins University 2006.

[3] Tchum SK, Newton S, Tanumihardjo SA, Fareed KNA, Tetteh A, Owuwu-Agyei S. Evaluation of a Green Leafy Vegetable Intervention in Ghanaian Postpartum Mothers. AJFAND 2009; 9: 1294-1307.

http://dx.doi.org/10.4314/ajfand.v9i6.46260

[4] Uchendu FN. Micronutrient Malnutrition, A Tragedy to Childhood Growth and Education Global Journal of Medical research. Volume 11, Issue 1 Version 1.0 May 2011. Type: Double Blind Peer Reviewed International Research Journal Publisher: Global Journals Inc. (USA) 2011, Online ISSN: 0975-5888

[5] World Bank Report India's Undernourished Children: A Call for Reform and Action 2007. http://siteresources.worldbank. org/HEALTHNUTRITIONANDPOPULATION/Resources/281 627-1095698140167/IndiaUndernourishedChildrenFinal.pdf.

[6] World Health Organization (WHO) and Food and Agriculture Organization of the United Nations (FAO). Vitamin and Mineral Requirements in Human Nutrition. 2nd Edition, Geneva 2004.

[7] Helen Keller International, Cameroon and Africa: Vitamin A Supplementation and Food Fortification Reducing Malnutrition and Preventing Blindness 2015.

[8] Honoré Tabuna and Micheline Tanoe. Facteurs explicatifs et développement de la consommation actuelle du safou (Dacryodes edulis) au Cameroun. World Agro Forestry Centre, West and Central Africa-Humid Tropic, 2010; p. 55.

[9] Abdollahi M, Mohammadi-Nasrabadi F, Houshiarrad A, Ghaffarpur M, Ghodsi D, Kalantari N. Socio-Economic Differences in Dietary Intakes: The Comprehensive Study on Household Food Consumption Patterns and Nutritional Status of Islamic Republic of Iran. Nutr Food Sci Res 2014; 1: 19-26.

[10] Fombang EN, Ngaha WD, Ejoh RA. Variability in Vitamin A Intake of Pregnant Women in Ngaoundere-Cameroon with Geographic Origin, Socio-Professional and Demographic Factors. Food and Nutr Sci 2016; 7: 74-82. http://dx.doi.org/10.4236/fns.2016.72009

[11] Anne Lebel and Emmanuelle Pontié. «Ngaoundéré», Le Cameroun aujourd'hui. Éditions du Jaguar, Paris 2011; pp. 179-183 (ISBN 978-2-86950-464-6)

[12] Mahmoudou D. Le pouvoir, le savoir et la richesse: Les Fulbe de Ngaoundéré face au processus de modernisation. Comparative Studies of Humanities and Social Sciences. Graduate School of Letters, Nagoya University 2008; p. 317.

[13] AOAC. Methods of Analysis of the Association of Official Analytical Chemists. AOAC; 10th Edition, Washington DC 2005.

[14] National Research Council. Recommended Dietary Allowances. National Academy Press, 10th Edition, Washington DC 1989.

[15] Stadlmayr B, Charrondiere UR, Enujiugha VN, Bayili RG Fagbohoun EG, Samb B, Addy P, Barikmo I, Ouattara F, Oshaug A, Akinyele I, Annor GA, Bomfeh K, Ene-Obong H, Smith IF, Thiam I, Burlingame B. West African Food Composition Table. The Food and Agriculture Organization of the United Nations (FAO), Rome 2012.

[16] Clive E, Fre W, Scholte PI, Schulting W, Jansen W, Hugo FF. Food composition table for Energy and Eight important nutrients in foods commonly eaten in East Africa. Technical 
Center of Agricultural and Rural Cooperation (ACP-EEC Lomé convention). Food and Nutrition Cooperation, a program of cooperation between countries of East, Central and Southern Africa 1987.

[17] Djuikwo VN, Ejoh RA, Gouado I, Mbofung CM, Tanumihardjo SA. Determination of Major Carotenoids in Processed Tropical Leafy Vegetables Indigenous to Africa. Food and Nutr Sci 2011; 2: 793-802. http://dx.doi.org/10.4236/fns.2011.28109

[18] Claire Matthieu D, Barrot L, Philippe C. Produits végétaux riches en carotènes: Fiches descriptives et pratiques à l'usage des pays sahéliens. Organisation Mondiale de la Santé 2001. http://apps.who.int/iris/bitstream/10665/70499/ 1/WHO_NHD_01.6_fre.pdf?ua=1

[19] Girma W, Genebo T. Determinants of Nutritional Status of Women and Children in Ethiopia. ORC Macro, Calverton 2002.
[20] Administration Committee on Coordination/Sub-Committee on Nutrition (ACC/SCN) Women and Nutrition. Symposium Report, Nutrition Policy Discussion 1990; Paper No. 6.

[21] Loaiza E. Maternal Nutritional Status. DHS Comparative Studies No. 24, Macro International Inc., Calverton 1997.

[22] Teller H, Yimar G. Levels and Determinants of Malnutrition in Adolescent and Adult Women in Southern Ethiopia. Eth $\mathrm{J}$ Health Dev 2000; 14: 57-66.

[23] Institut National de la Statistique (INS) et ICF International. Enquête Démographique et de Santé et à Indicateurs Multiples du Cameroun (EDS-MICS) 2011. INS et ICF International, Calverton 2012 